\title{
Integrating Unmanned Aircraft Systems into the National Airspace System
}

\author{
Robert Concannon \\ General Atomics Aeronautical Systems Incorporated \\ D. Scott Worrells \\ Embry-Riddle Aeronautical University - Worldwide
}

\begin{abstract}
The unmanned aircraft systems (UASs) community is waiting to take full advantage of the U.S. National Airspace System (NAS). One concern that must be addressed before UASs can be integrated into the UAS is whether or not the UASs community is open and receptive to recommendations regarding safety. In April of 2006, a Customs and Border Protection (CBP) MQ-9 Predator B crashed. The National Transportation and Safety Board (NTSB) investigated the accident; the board's final report included a number of recommendations for improving operations of UASs in the NAS. This study discusses the actions taken by the CBP and General Atomics Aeronautical Systems Incorporated (GAASI) in response to the NTSB's Safety Recommendations following their accident investigation. The extent to which the board's recommendations were incorporated will provide insight into the feasibility of incorporating UASs into the NAS. Overall findings reveal an age range of 39 to 59 years of age of predominantly white male pilots and sensor operators. Federal Aviation Administration certificated pilots: 41.0\% Commercial pilots; 43.6\% Air Transport pilots; 51.3\% flight instructors; and 74.4\% with instrument ratings. Forty one percent of those with a pilot certificate had relied on military experience to acquire those certificates. Eighty eight percent of the respondents were predominantly in agreement that the UAS community was receptive to NTSB safety recommendations. Respondents mostly disagreed that the UAS community was receptive to the recording of conversations. Respondents predominantly disagreed that contemporary aspects of human factors had been designed into operator control interfaces and Ground Control System layout.
\end{abstract}

\section{Introduction}

On April 25, 2006, about 0350 Mountain Standard Time, a MQ-9 (Predator B) aircraft, serial number BP-101, call sign OMAHA 10, collided with the terrain approximately 10 nautical miles northwest of the Nogales International Airport, Nogales, AZ. The UAS was owned by U.S. CBP and operated as a public-use aircraft (Sullivan \& Keenan, 2006). This was the first UAV accident that was investigated by the NTSB. Up to that point in time the majority of UAV crashes took place in combat environments or in restricted airspace that are beyond the purview of civilian aviation authorities.

Unmanned Aircraft Systems development has not undergone the same level of scrutiny as manned aircraft system development. For example, while still under development the unarmed Predator A (RQ-1) was put into service and flew its first 
combat missions in 1995. The RQ-1 underwent many changes in an attempt to keep up with U.S. Air Force demands. The requirement for ever-present eyes in the sky, in various combat theaters around the world, led the Department of Defense to skip the normal test and evaluation process that would have been required to develop a manned aircraft system. Development moved quickly from the RQ-1 to an armed version of Predator A (MQ-1) and shortly thereafter the larger Predator B (MQ-9). The combat driven nature of the UASs' community brought about a "make do" culture that eventually became a contributing factor in the loss of Omaha 10.

This lack of stringent test and evaluation, typical of manned systems development, allowed some design errors in Ground Control Stations (GCSs) to go unnoticed. Lack of human factors engineers in the initial program amplified the problems. Human factors engineers may have seen errors early on and encouraged modification of GCSs to avoid long term problems.

The GCSs were designed more like a computer than an aircraft cockpit. Common tasks for pilots in a cockpit were counterintuitive in computer engineer designed GCSs. Customs and Border Protection used pilots of varying experience levels and backgrounds to control their aircraft. Minimum requirements for CBP pilots in 2006 were approximately 1500 hours of flying time and a commercial pilot license with an instrument rating.

\section{Review of Relevant Literature and Research}

Unmanned aircraft (UA) are not a new idea. Unmanned aircraft go back to ballooning and early powered flight. The beginning of unmanned powered flight starts in World War I when the Royal Flying Corps took the gyro stabilized compass and radio controls that were still in their infancy and developed the flying bomb. At the same time the U.S. Army Air Corps was developing the Kettering Bug, another ill-fated project. These projects were not successful, but were the technology base that led to further developments. Germany had the best known unmanned system in World War II with their V-1 buzz bombs. These systems had little strategic success but were excellent terror weapons and caused British forces to spend a large amount of their assets defending against V-1 attacks (Yenne, 2004).

Allied forces also had a number of unmanned systems but they were completely unknown to the public. Modified B-17s and B-24s were launched with flight crews onboard. When the aircraft were at cruise altitude the crew bailed out over friendly territory and control was handed over to a chase aircraft using radio controls (Yenne, 2004).

Unmanned aircraft continued to be developed for military use with each passing world conflict. In 1982 Israel was concerned with Syrian forces controlling a section of Lebanon known as the Bekaa Valley; at that time the most heavily defended airspace in 
the world. Israeli forces used UASs to beam live video pictures of Syrian forces to Israel. Israeli forces also used UASs as decoys. In an air battle that lasted approximately two hours all Syrian surface to air missile sites were destroyed. There were no manned aircraft lost by Israeli forces. This battle changed how the world looked at UA and has affected the design and use of UASs since that time (Clary, 1988).

Unmanned Aircraft Systems can provide a level of persistence and stamina that far exceeds human capacity and, by removing humans from aircraft, UASs provide options for risk taking and risk avoidance not previously available with a manned platform ("U.S. Department,” 2005).

Unmanned Aerial Vehicles have continued to advance and the means by which they are controlled has advanced as well. Initially, Unmanned Aerial Vehicles (UAVs) could only fly within line of site of the control station; satellite telemetry has enabled global control from GCSs that may be fixed or mobile.

The UAV industry grew rapidly based largely upon military demands. Manufacturers of UASs have developed their own proprietary means of communications and control, with little or no standardization between manufacturers. This became problematic, even for the military, and standardization became an issue. Accordingly, the North Atlantic Treaty Organization has accepted STANAG (Standard Agreement) 4586 for increased interoperability for GCSs. Some U.S. manufacturers are using this standard in the development of common GCSs in the hope of developing a common mental model that crosses multiple airframes (Cummings, Kirschbaum, Sulmistras, \& Platts, n.d.).

All UASs must have a GCS of some sort and they all perform some or all of three main functions of mission planning, control, and data manipulation. The ability for GCSs to perform these functions is system dependent (Anderson, 2002). Some GCSs are completely automated with pushbutton commands for takeoff and landing. Others require that a pilot manually control aircraft for all or part of the flight. There are as many variations as there are aircraft systems. Some systems have missions planned and sent to UASs prior to launch, while others are planned on the fly (Doherty et al., 2000).

There is a move to develop systems that will coordinate and control multiple aircraft. Coordination of multiple unmanned aircraft will give planners a huge advantage in combat mission planning (McLain, 1999). While some researchers are looking at ways to coordinate and control multiple unmanned aircraft (Diamond, Rutherford, \& Taylor, 2009), there needs to be more focus on how to integrate UASs into the NAS.

The manufacturers of UASs are looking to civil and commercial applications for their aircraft, especially applications characterized as dull, dangerous, or dirty. There are many applications such as pipeline inspection, border security, firefighting, agricultural management, communications relay, and air-freight operations that are particularly suited 
for unmanned aircraft (Hayhurst et al., 2007). Unmanned Aircraft Systems can also act as inexpensive highly mobile satellites for communications and data collection.

Acceptance of UASs into the NAS by the Federal Aviation Administration (FAA) will require that UASs' community improve its safety record. Mishap rates for Predator aircraft are almost 30 times greater than that of manned aircraft (Nullmeyer, Herz, \& Montijo, 2009).

Most UASs are flown overseas in combat areas or in restricted airspace in the US. Accidents that happen in those locations are outside the span of influence of the FAA and NTSB. There are a few UASs that are flown in the NAS with FAA approval. Unmanned Aircraft Systems operation within the NAS require a Certificate of Authorization (COA) from the FAA (NTSB, 2007). Accordingly, when Omaha 10 crashed in the Arizona desert the investigation fell under the auspices of the NTSB.

In April of 2006, the NTSB started its first investigation of an UA accident. This investigation resulted in 22 safety recommendations issued to GA-ASI and CBP (Werfelman, 2007). Errors of commission and omission led directly to the loss of Omaha 10. The pilot failed to follow checklist procedures after the pilot payload operator (PPO1 ), suffered a rack lock up resulting in an unintended engine shut off and eventual loss of aircraft (Sullivan \& Keenan, 2006).

The GCS is the equivalent of the cockpit in a manned aircraft. In a manned aircraft the controls on the left and right position perform the same task. The controls on both sides of Predator GCSs are identical too, however they have different functions depending on whether a position is a designated pilot station or a designated sensor operator station. Changing the designation (pilot/sensor operator) of a station is called a "rack switch." Proper configuration of controls, levers, and switches is essential during rack switch. The position of the condition lever at the time of the rack switch caused the engine to shut down in the Omaha 10 accident (Carrigan, Long, Cummings, \& Duffner, 2008).

The Omaha 10 engine failure was not an isolated event. In 2004 a GA-ASI' Altair aircraft encountered a similar rack lock and switch and, with switches in the wrong position resulted in an unintended engine shutdown. The pilot restarted the engine and was able to safely recover the aircraft (Williams, 2006). On another occasion, an Army Shadow was lost when the engine shut off command was accidentally sent to the aircraft while it was returning to land (Williams, 2006).

A cohesive integration of UASs into the NAS is dependent upon the UASs' community to adapt to FAA regulation and scrutiny. The FAA has a mandate to open U.S. airspace to military, commercial, and privately owned UASs by September 30, 2015. Successful integration of UASs into NAS should enable considerable economic growth (Koenig, 2012). 


\section{Methodology}

\section{Research Model}

The researchers' intent was to collect data from UASs' crew members from those sections of UASs' community that are currently operating GA-ASI UASs within the NAS. A mixed method approach to data collection and analysis was used whereby qualitative data was gathered based upon participant's extent of agreement on 19 Likert scale questions and quantitative data was gathered from participants reporting on specific demographic criteria.

Survey population. The total population of pilots and sensor operators currently involved with these specific UASs was fewer than 100 individuals. United States CBP personnel and civilian personnel operating UASs as government employees (Government Contractors), make up the population for this study.

Survey instrument. The data collection device was a mixed method survey designed by the researchers. There were 31 questions that consisted of 10 Demographic questions, 2 Organizational questions, and 19 Operational questions (Likert scale).

The survey instrument was developed through an iterative process between the two researchers. Once the instrument had been reviewed and approved by the Institutional Review Board of Embry-Riddle Aeronautical University the survey was distributed to an expert panel made up of subject matter experts and academics experienced in data collection and analysis. Comments/suggestions of the expert panel were reviewed, incorporated as appropriate, and the instrument was deemed valid.

The Likert questions were based upon a scale of agreement: Strongly Agree; Agree; Undecided; Disagree; and Strongly Disagree. Fourteen of the 19 Likert scale questions were directly related to NTSB recommendations from the Omaha 10 accident investigation, 2 questions were related to contemporary human factors issues, 2 questions were related to recurrent training requirements, and 1 question was related to the implementation of a "Safety Plan" into UASs' operations. The survey was designed to determine the extent to which UASs' community had addressed the recommendations from the NTSB's Omaha 10 accident investigation. Respondents were also provided the opportunity to make additional comments at the end of the survey.

Participant confidentiality was protected to the greatest extent possible. Participants were notified that they could terminate their participation at any time. The survey instrument received appropriate Institutional Review Board approval prior to its use in any capacity. 


\section{Distribution Method}

For the greatest possible dissemination and ease of response, an internet-based method of distribution was used. Letters of introduction were sent to CBP and corporate leadership at all known locations asking that they help to promote the research. Direct emails were sent when possible to members of the organizations to encourage the use of the survey with the request that it be shared with co-workers. The survey was made available on March 25, 2012, and it was active for 90 days. The first response was recorded on March 30, 2012, the last response was recorded on May 30, 2012.

\section{Treatment of the Data}

Forty-three surveys were returned within 90-days of the survey being made available on Survey Monkey. Two of these responses were readily rejected because they were not completed. Two other responses were rejected due to a number of inconsistencies; responding to multiple choice questions by selecting all of the choices, including "none" and "prefer not to answer." Accordingly, out of the 43 original responses 39 were determined to be useable. Out of these 39 responses there were two questions in which there were 38 responses, no rationale was provided, and $\mathrm{N}$ was adjusted to reflect an accurate response rate.

\section{Findings}

The researchers believe that a profile of UAS community is a key component of the overarching question as to whether or not UASs can be safely integrated into the NAS. Who are these rather innocuous individuals, how old are they, what gender are they, what is their experience based upon, and to what extent are they familiar with safe operations within the NAS? These are just a few of the questions posed to those participating in this study. A thorough description of pilot and sensor operators follows.

\section{Background and Demographic Environment}

Nineteen of those responding (48.7\%) indicated they were in the 25 to 38 year age range, 16 respondents (41.0\%) indicated they were in the 39 to 59 year age range, and 2 respondents (5.1\%) indicated they were in the 60 years plus age range. Two respondents (5.1\%) indicated they "Prefer Not to Answer" the question. Thirty-six (92.3\%) of those responding indicated they were male, no respondents indicated they were female, three respondents (7.7\%) indicated they "Prefer Not to Answer" the question. Thirty-three respondents (84.6\%) indicated post-secondary degrees; 23 (59.0\%) having a bachelor's degree and $10(25.6 \%)$ having a graduate degree. See Table 1 for responses to the question: "Which of the following best describes your racial/ethnic group?" 
Table 1

Racial Ethnic Breakdown

\begin{tabular}{lcc}
\hline Race/Ethnicity & $\begin{array}{c}\text { Number } \\
\text { Responding }\end{array}$ & $\begin{array}{c}\text { Percentage } \\
\mathrm{N}=39\end{array}$ \\
\hline African American/Black & 1 & $2.6 \%$ \\
American Indian/Alaska Native & 0 & $0.0 \%$ \\
Asian American/Asian & 0 & $0.0 \%$ \\
Caucasian/White & 33 & $84.6 \%$ \\
Native Hawaiian/Pacific Islander & 0 & $0.0 \%$ \\
Hispanic or Latino & 2 & $5.1 \%$ \\
Prefer Not to Answer & 2 & $5.1 \%$ \\
\hline
\end{tabular}

See Table 2 for responses to the question: "Please identify the type of Flight Instructor certificates(s) you possess (check all that apply).”

Table 2

Type of Flight Instructor

\begin{tabular}{lcc} 
& Number & Percentage \\
Certified Flight Instructor (CFI) Type & Responding & N $=39$ \\
\hline None & 16 & $41.0 \%$ \\
CFI only & 3 & $7.7 \%$ \\
CFI Instrument & 5 & $12.8 \%$ \\
CFI and Multi-engine & 3 & $7.7 \%$ \\
CFI, Multi-engine, Instrument & 12 & $30.8 \%$ \\
\hline
\end{tabular}

Thirty-four respondents (87.2\%) indicated they did not possess any non-pilot FAA issued certificates. Two respondents (5.1\%) indicated possession of a Mechanic License with Airframe and Powerplant ratings, one respondent (2.6\%) indicated possession of Mechanic

License with Repairman rating, one respondent (2.6\%) indicated possession of an Air Traffic Controller certificate, and one respondent (2.6\%) indicated possession of a Flight Engineer certificate.

Sixteen respondents (41.0\%) indicated that their FAA certificates were based upon military competency, 23 respondents (59.0\%) indicated that their FAA certificates were not based upon military competency.

Twelve respondents (30.8\%) indicated that some of their UAS/UAV experience was based upon military experience; four of these respondents $(10.3 \%)$ indicated $100 \%$ of their UAS/UAV experience was based upon military experience. Thirty one respondents (79.5\%) indicated that some of their UAS/UAV experience was based upon CBP experience; 20 of these respondents (51.3\%) indicated that $100 \%$ of their UAS/UAV experience was based upon CBP experience. Thirteen respondents (33.3\%) indicated that 
some of their UAS/UAV experience was from a source other than the military or CBP; of these respondents $4(10.3 \%)$ indicated that $100 \%$ of their UAS/UAV experience was based upon a source other than the military or CBP; the source of this experience was not provided.

Thirty-three respondents (84.6\%) indicated they had logged 38,263 hours as pilot for an average of 1,159.0 hours per pilot, 19 respondents (48.7\%) indicated they had logged 14,175 hours as a sensor operator for an average of 746.1 hours per sensor operator, and 3 respondents (7.7\%) indicated that had logged 9800 hours as "Other" for an average of 3,266.7 hours each; "other" was not specified.

\section{Organizational}

Twenty-six respondents (66.6\%) indicated CBP and 13 respondents (33.3\%) indicated civilian contractor as their place of employment. Six respondents $(15.4 \%)$ indicated GA-ASI as their employer, two respondents (5.1\%) indicated Crew Training International as their employer, one respondent (2.6\%) indicated University of North Dakota/GA-ASI as their employer, and one respondent (2.6\%) indicated "Prefer Not to Answer."

See Table 3 for responses to the question: "Please identify all flight related FAA issued certificates/ratings you possess (check all that apply).”

Twenty-two respondents (57.9\%) indicated pilot, seven respondents (18.4\%) indicated sensor operator, and nine respondents (23.7\%) indicated pilot/sensor operator. One respondent did not answer this question; no rationale was provided and $\mathrm{N}$ was adjusted from 39 to 38 .

\section{Operational}

In this section of the survey 14 of the 19 questions asked were directly related to the NTSB's Safety Recommendations based upon its investigation into the Omaha 10 accident. Two questions were related to contemporary human factors issues, two questions were related to re-currency training requirements, and one question was related to whether or not a Safety Plan had been implemented. Please see Table 4. 
Table 3

Federal Aviation Administration Issued Certificates/Ratings

\begin{tabular}{|c|c|c|}
\hline Certificate/Rating & $\begin{array}{c}\text { Number } \\
\text { Responding }\end{array}$ & $\begin{array}{c}\text { Percentage } \\
\mathrm{N}=39 \\
\end{array}$ \\
\hline \multicolumn{3}{|l|}{ Certificate } \\
\hline None & 5 & $12.8 \%$ \\
\hline Student Pilot & 1 & $2.6 \%$ \\
\hline Sport Pilot & 0 & $0.0 \%$ \\
\hline Recreational Pilot & 0 & $0.0 \%$ \\
\hline Private Pilot & 9 & $23.1 \%$ \\
\hline Commercial Pilot $^{\mathrm{a}}$ & 16 & $41.0 \%$ \\
\hline Air Transport Pilot ${ }^{b}$ & 17 & $43.6 \%$ \\
\hline \multicolumn{3}{|l|}{ Rating } \\
\hline Flight Instructor $^{c}$ & 20 & $51.3 \%$ \\
\hline Instrument & 29 & $74.4 \%$ \\
\hline Single Engine & 27 & $69.2 \%$ \\
\hline Multi Engine & 30 & $76.9 \%$ \\
\hline Land & 31 & $79.5 \%$ \\
\hline Sea & 4 & $10.3 \%$ \\
\hline \multicolumn{3}{|c|}{$\begin{array}{l}\text { Note. }{ }^{\mathrm{a} C o m m e r c i a l ~ P i l o t ~ r e p o r t e d ~ e x c l u s i v e ~ o f ~ A i r ~ T r a n s p o r t ~ P i l o t ~ c e r t i f i c a t e . ~}{ }^{\mathrm{b}} \text { Air } \\
\text { Transport Pilot as reported is inclusive of Commercial Pilot with the exception of one Air } \\
\text { Transport Pilot only without Commercial Pilot being reported. }{ }^{\mathrm{C}} \text { In the previous question } \\
\text { respondents reported a total of } 23 \text { Flight Instructor Ratings, responses to this question } \\
\text { indicate } 20 \text { Flight Instructor ratings. This may be due to duplicate reporting related to } \\
\text { Certified Flight Instructor, Certified Flight Instructor Instrument, Certified Flight } \\
\text { Instructor Multi Engine, etc. }\end{array}$} \\
\hline
\end{tabular}


Table 4

Survey Results: Extent of Agreement

Response $(\mathrm{N}=39 *)$

Question

13. The UAS on which you are a crew member has SA $\quad$ A $\quad$ U $\quad$ D $\quad$ SD measures in place to prevent inadvertent engine shutdown.

14. The UAS on which you are a crew member $\quad \begin{array}{llllll}23 & 14 & 1 & 1 & 0\end{array}$ ensures that the transponder continues to provide beacon code ... if an engine shuts down in flight.

15. The UAS on which you are a crew member has $\begin{array}{llllll}9 & 19 & 5 & 5 & 1\end{array}$ adequate visual indications of safety-critical faults, such as engine-out conditions and console lockups.

$\begin{array}{lllllll}\text { 16. The UAS on which you are a crew member has } & 7 & 17 & 7 & 6 & 2\end{array}$ adequate aural indications of safety-critical faults ....

17. Unit developed lost-link mission profiles $\quad \begin{array}{llllll}32 & 6 & 0 & 0 & 0\end{array}$ to ensure that lost-link mission routes minimize the potential safety impact ....

18. Organization developed lost-link mission $\quad \begin{array}{llllll}33 & 6 & 0 & 0 & 0\end{array}$ profiles to ensure ... the aircraft will proceed to a safe zone for flight termination.

19. Organization requires that UAS crew members $\begin{array}{rlllll}28 & 10 & 1 & 0 & 0\end{array}$ be trained concerning ... performance and flight path ... during a lost-link mission.

20. The UAS on which I am crew of has a $\quad \begin{array}{llllll}15 & 17 & 4 & 2 & 1\end{array}$ means of restarting ... that is autonomous, not requiring link with the GCS.

$\begin{array}{llllll}\text { 21. Organization participates in periodic operational } & 7 & 15 & 10 & 6 & 1\end{array}$ reviews ... for standard and nonstandard UA operations (Continental U.S. operations only).

$\begin{array}{lllllll}\text { 22. Organization has taken adequate steps to } & 13 & 15 & 7 & 3 & 1\end{array}$ identify and correct the causes of console lockups.

23. My organization has implemented a training $\quad \begin{array}{llllllll}17 & 13 & 4 & 5 & 0\end{array}$ program to ensure aircrew knowledge and proficiency in executing emergency procedures. 


\begin{tabular}{|c|c|c|c|c|c|}
\hline Question & SA & $\mathrm{A}$ & $\mathrm{U}$ & $\mathrm{D}$ & $\mathrm{SD}$ \\
\hline $\begin{array}{l}\text { 24. My organization requires that a backup pilot ... } \\
\text { be readily available during UAS operations. }\end{array}$ & 12 & 14 & 10 & 2 & 1 \\
\hline $\begin{array}{l}\text { 25. My organization developed a safety plan, which } \\
\text { ensures that hazards... are identified and that } \\
\text { necessary actions are taken to mitigate the } \\
\text { corresponding safety risks to the public. }\end{array}$ & 20 & 15 & 3 & 1 & 0 \\
\hline $\begin{array}{l}\text { 26. My organization requires all conversations } \\
\ldots \text { be recorded and retained to support accident } \\
\text { investigations. }\end{array}$ & 6 & 10 & 6 & 11 & 6 \\
\hline $\begin{array}{l}\text { 27. My organization requires that all telephone } \\
\text { conversations, to and from the GCS, be recorded } \\
\text { and retained to support accident investigations. }\end{array}$ & 0 & 4 & 11 & 17 & 7 \\
\hline $\begin{array}{l}\text { 28. Contemporary aspects of HF engineering } \\
\text { have been designed into the pilot and sensor operc } \\
\text { control interfaces on the UAS .... }\end{array}$ & $\begin{array}{r}2 \\
\text { ator }\end{array}$ & 11 & 5 & 10 & 11 \\
\hline $\begin{array}{l}\text { 29. Contemporary aspects of HF engineering } \\
\text { have been designed into the layout of the GCS of } \\
\text { which I am a crewmember. }\end{array}$ & 3 & 7 & 7 & 14 & 8 \\
\hline $\begin{array}{l}\text { 30. Organization requires annual re-currency training } \\
\text { in aircraft systems and in emergency procedures } \mathrm{f} \\
\text { the manned aircraft I fly. }\end{array}$ & & 11 & 5 & 4 & 2 \\
\hline $\begin{array}{l}\text { 31. Organization requires annual re-currency training } \\
\text { in aircraft systems and in emergency procedures } \mathrm{f} \\
\text { the unmanned aircraft that I fly }\end{array}$ & & 10 & 2 & 6 & 3 \\
\hline
\end{tabular}

Note. *In question 17 one respondent did not answer the question and $\mathrm{N}$ was adjusted to 38.

\section{Discussion}

Data was collected using a survey that asked for demographic information, organizational affiliation, and UASs crew member's extent of agreement on UASs' community's response to the NTSB Safety Recommendations from the Omaha 10 accident investigation. Two human factors questions that were not related to the NTSB Safety Recommendation were also included. The survey did not require that those answering the survey to be aware of the accident or the NTSB findings.

\section{Demographics}

The data indicates that respondents were predominantly between the ages of 25 to 45 (74.4\%), men (92.3\%), and Caucasian/white ethnicity (84.6\%). Thirty-three respondents 
(84.6\%) indicated they possessed a post-secondary degree, 10 (25.6\%) indicated they had completed a graduate degree.

Survey results indicate a large number of respondents were certificated by the FAA in a variety of pilot and non-pilot categories. In the pilot categories 16 respondents $(41.0 \%)$ indicated possession of a Commercial Pilot certificate, 17 respondents (43.6\%) indicated possession of an Air Transport Pilot certificate, 23 respondents (59.0\%) indicated possession of Certified Flight Instructor certificate, 29 respondents (74.4\%) indicated possession of an Instrument rating, and 30 respondents (76.9\%) indicated possession of a Multi-engine rating. In the non-pilot categories two respondents (5.1\%) indicated possession of a Mechanic license with Airframe and Power Plant ratings; one respondent (2.6\%) indicated possession of a Repairman's license; one respondent (2.6\%) indicated possession of an Air Traffic Controller certificate; and one respondent (2.6\%) indicated possession of a Flight Engineer certificate.

An important finding related to the demographic data is the extent of FAA pilot certifications and associated ratings. Thirty-three respondents (84.6\%) indicated possession of either a Commercial Pilot certificate or an Air Transport Pilot certificate. Twenty-three respondents (59.0\%) indicated they were flight instructor rated and 29 respondents $(74.4 \%)$ indicated they were instrument rated. These numbers indicate that UASs pilots and sensor operators participating in this study are familiar with FAA policies, procedures, and regulations for the safe operation of aircraft in the NAS. These numbers are important because they reflect extensive qualification and practical experience in the safe operation of aircraft in the NAS. This finding is supported by the literature which indicates that CBP requires FAA Commercial Pilot certificates and Instrument ratings of their UASs pilots.

\section{Organization Affiliation}

Sixty-six percent of survey respondents indicated they were employed by CBP and 33.3\% indicated Civilian Contractor. This response illustrates the environment from which future pilots and sensor operators will have acquired their experience. This is important considering this government-based experience will establish the foundation for the future of UASs operations in the NAS. Of those respondents indicating employment by a civilian contractor: (a) six (15.4\%) indicated GA-ASI; (b) two (5.1\%) indicated Crew Training International; (c) one (2.6\%) indicated University of North Dakota/GAASI; and (d) one Preferred Not to Answer. Survey results indicate the majority of respondents were either UAS pilots (57.9\%) or UAS pilots/sensor operators (23.7\%). The researchers anticipate that the numbers of pilots and sensor operators will become relatively equal over time. 


\section{National Transportation Safety Board Safety Recommendations}

Fourteen of the questions on the survey were specifically based upon the NTSB Safety Recommendations following the Omaha 10 accident investigation (NTSB, 2007). These safety recommendations were used to craft either a question or a statement in which respondents could express their extent of agreement on a five point Likert scale. This was done to determine to what extent respondents agreed that CBP had incorporated the recommendations into UASs flight operations. The questions that were developed addressed only those safety recommendations that researchers believed were relevant to the intent of the study. Accordingly, Safety Recommendations A-07-75, and A-07-80 through A-07-83 were not addressed in the study. The findings are reported as they relate to central tendency: Mode and Median are illustrated in Table 5. Calculations of central tendency were based upon those answering each respective question. The alpha-numeric in parenthesis, for example (Q13), provides a cross-reference from the safety recommendations to the corresponding questions.

Recommendation A-07-70 (Q13). Modify the UAS to ensure inadvertent engine shutdown does not occur. Software and hardware were changed by GA-ASI to eliminate inadvertent engine shutdowns. Accordingly, 34 survey respondents (87.2\%) "Strongly Agree" or "Agree" that these changes have significantly reduced inadvertent engine shutdowns, 3 respondents (7.7\%) disagree, and 2 respondents (5.3\%) were undecided.

Recommendation A-07-71 (Q15/16). Establish adequate visual and aural indications of safety-critical faults, such as engine-out conditions and console lockups, and present them in order of priority, based on the urgency for pilot awareness and response. Twentyeight survey respondents (71.8\%) "Strongly Agree” or "Agree" that adequate visual indications of safety-critical faults have been established, six respondents (15.4\%) did not agree, and five respondents (12.8\%) were undecided. Twenty-four respondents $(61.5 \%)$ "Strongly Agree" or "Agree" that adequate aural indications of safety-critical faults have been established, eight respondents (20.5\%) indicated they did not agree, and seven respondents $(17.9 \%)$ were undecided.

Recommendation A-07-72 (Q17/18). Develop lost link mission profile routes minimizing safety risk to persons on the ground, optimizing potential to recover data-link of the aircraft, and provide for a safe crash zone if the aircraft cannot be recovered. Thirty-eight survey respondents (100\%) "Strongly Agree” or “Agree” that lost-link missions routes minimize the potential safety impact to persons on the ground and optimize the ability to recover the data-link. One survey respondent did not answer this question, no rationale was provided and $\mathrm{N}$ was adjusted down to 38 for this question. Thirty-nine respondents (100\%) "Strongly Agree" or "Agree” that in the absence of datalink recovery, the UAV will proceed to a safe zone for flight termination. It is interesting to note that there were no "Undecided," “Disagree," or "Strongly Disagree" responses related to Recommendations A-07-72. 
Recommendation A-07-73 (Q19). Pilots be trained in expected performance and flight path of the UA during a lost-link mission. Thirty-eight survey respondents (97.4\%)

Table 5

Survey Results: Measures of Central Tendency

Question (Q)

Response $(\mathrm{N}=39 *)$

13. The UAS on which you are a crew member has Mode

measures in place to prevent inadvertent engine shutdown.

14. The UAS on which you are a crew member ensures that the transponder continues to provide beacon code ... if an engine shuts down in flight.

15. The UAS on which you are a crew member has 5 Median adequate visual indications of safety-critical faults, such as engine-out conditions and console lockups.

16. The UAS on which you are a crew member has adequate aural indications of safety-critical faults ....

17. My flying unit developed lost-link mission profiles to ensure that lost-link mission routes minimize the potential safety impact ....

18. My flying organization developed lost-link mission profiles to ensure ... the aircraft will proceed to a safe zone for flight termination.

19. My organization requires that UAS crew members be trained concerning ... performance and flight path ... during a lost-link mission.

20. The UAS on which I am a crew member of has a

5

4

4

5

5

5

4

4

4

5

4 be readily available during UAS operations. 
Question (Q)

25. My organization has developed a safety plan, which ensures that hazards... are identified and that necessary actions are taken to mitigate the corresponding safety risks to the public.

26. My organization requires that all conversations ... be recorded and retained to support accident investigations.

27. My organization requires that all telephone conversations, to and from the GCS, be recorded and retained to support accident investigations.

28. Contemporary aspects of human factors engineering have been designed into the pilot and sensor operator control interfaces on the UAS ....

29. Contemporary aspects of human factors engineering have been designed into the layout of the GCS of which I am a crewmember.

30. My organization requires annual re-currency training in aircraft systems and in emergency procedures for the manned aircraft I fly.

31. My organization requires annual re-currency training in aircraft systems and in emergency procedures for the unmanned aircraft that I fly.

Note. ${ }^{*}$ In question 17 one respondent did not answer the question and $\mathrm{N}$ was adjusted to 38.

"Strongly Agree" or "Agree" that UAS operators receive training in how to respond in a lost-link mission scenario.

Recommendation A-07-74 (Q14). Transponders should to continue to operate normally even if the engine shuts down in flight and, if the transponder fails, that the pilot receives a clear indication. Thirty-seven survey respondents (94.9\%) "Strongly Agree” or "Agree" that transponders will continue to operate normally, in all modes even if an engine shuts down in flight. The operations handbook states that this is true and that if the aircraft is lost-link, transponders will transmit the code associated with the lost-link mission.

Recommendation A-07-76 (Q20). Develop a means of restarting the UA engine during a lost-link emergency mission profile that is autonomous, not requiring data-link with the GCS. Thirty-two survey respondents (82.1\%) "Strongly Agree” or “Agree” that the UA has a means of restarting the engine during a lost-link emergency mission profile that does not rely on line-of-sight control. However, three respondents (7.7\%) "Disagree" or "Strongly Disagree" that the improvement to UA software has adequately addressed this recommendation. 
Recommendation A-07-77 (Q21). The UASs' community and local Air Traffic Control should participate in periodic operational reviews between UAS operation teams and local air traffic control facilities, with specific emphasis on face-to-face coordination between the working-level controller and UA pilot(s), to clearly define responsibilities and actions required for standard and nonstandard UA operations. Twenty-two survey respondents (56.4\%) "Strongly Agree" or "Agree" that this recommendation has been addressed. Seven respondents (17.9\%) "Strongly Disagree" or "Disagree." Although these numbers would indicate the majority of respondents agree that the recommendation has been addressed, it is interesting to note that 10 respondents (25.6\%) were "Undecided." It would appear that there is either a communications breakdown across CBP or that this recommendation is handled differently at each flight location. The level of confidentiality of the survey prohibits a determination of where each respondent is geographically assigned.

Recommendation A-07-78 (Q26/27). All conversations, including telephone conversations, between UA pilots and air traffic control, other UA pilots, and other assets that provide operational support to UA operations, be recorded and retained to support accident investigations. Sixteen respondents (41.0\%) "Strongly Agree" or "Agree," 17 respondents (43.6\%) "Strongly Disagree" or "Disagree," and 6 respondents (15.4\%) were "Undecided" that all radio transmissions were being recorded and retained to support accident investigations. No respondents indicated "Strongly Agree," 4 respondents (10.3\%) "Agree," 24 respondents (61.5\%) "Strongly Disagree" or "Disagree," and 11 respondents (28.2\%) were "Undecided" that all GCS telephone conversations were being recorded and retained to support accident investigations. The extent of disagreement with these two statements is interesting. These responses are most likely a result of the "security" environment in which the respondents work. However, waving the security flag does not discount the need to record information that can be used in accident investigations. The results of these two questions reveal an area that will need to be addressed to ensure a cohesive existence between UASs' operations and manned aircraft operations in the NAS.

Recommendation A-07-79 (Q22). Investigate and resolve the cause of console lockups. Twenty-eight survey respondents (71.8\%) "Strongly Agree" or "Agree" and four respondents (10.3\%) "Strongly Disagree" or "Disagree" that adequate steps to identify and correct the causes of console lockups have been taken. Although seven respondents (17.9\%) indicated they were "Undecided" on the corrective action taken the number of respondents in agreement indicates this recommendation has been addressed to a significant extent. However, the numbers of undecided, disagree, and strongly disagree responses should not go unnoticed. Contractors showed a higher positive response than CBP employees. This may be due to their greater longevity in the program and their having seen improvements in console lock-ups over time. Education in console lock-ups and ways to prevent them should be stressed in basic and refresher training. 
Recommendations A-07-84 (Q23). Revise U.S. CBP's pilot training program to ensure pilot proficiency in executing emergency procedures. Thirty survey respondents (76.9\%) "Strongly Agree" or "Agree" that emergency procedures training has been implemented. There were five respondents (12.8\%) that "Disagree" and four respondents (10.3\%) that were "Undecided." This data implies that emergency procedure training has been put into place and is currently incorporated as part of the normal flying practices at CBP. These responses are perplexing and quite diverse. A vast majority of respondents recognized the implementation of emergency procedures while nine respondents either disagree or were undecided that emergency procedures had been implemented.

Recommendation A-07-85 (Q24). Make backup crew members available. Twentysix survey respondents (66.6\%) "Strongly Agree" or "Agree" and three respondents (7.7\%) "Strongly Disagree" or "Disagree" that this recommendation has been addressed. Ten respondents (25.6\%) indicated they were "Undecided." Although this number is relatively small, when combined with respondents that indicated some level of disagreement, a total of 13 respondents representing 33.3\% of those responding, have reservations regarding the implementation of corrective measures that address this issue.

\section{Human Factors}

Participants were asked two questions related to contemporary aspects of human factors. These two questions (Q28/29) do not pertain to a specific NTSB Safety Recommendation. However, researchers believed it was pertinent to ask UASs Pilots and Sensor Operators their opinion on these two contemporary aspects of human factors.

Thirteen survey respondents (33.3\%) "Strongly Agree" or "Agree,” 21 respondents (53.8\%) "Strongly Disagree" or "Disagree," and 5 respondents (12.8\%) were "Undecided" that contemporary aspects of human factors have been designed into the pilot and sensor operator control interfaces. Twenty-one respondents (53.8\%) "Disagree," or "Strongly Disagree," that human factors have been addressed in the design of pilot and sensor operator control interfaces; 5 respondents (12.8\%) were undecided.

Ten survey respondents (25.6\%) "Strongly Agree" or "Agree," 22 respondents (56.4\%) "Strongly Disagree" or "Disagree," and 7 respondents (17.9\%) were "Undecided" that aspects of human factors have been designed into GCSs layout. Twenty-two respondents (56.4\%) "Disagree," or "Strongly Disagree," that human factors have been addressed in the design of GCS layout; 7 respondents (17.9\%) were undecided.

The responses to these two questions indicate, as far as those responding to the survey are concerned, that the majority of UASs' pilots and sensor operators are undecided or disagree that contemporary human factor aspects have been incorporated into the design of UASs. Although not related to a specific NTSB Safety Recommendation, these responses are an important finding of the study. The attention and commitment to Human 
Factors in UASs/GCSs will need to mirror that of the FAA and manned aircraft systems to ensure a cohesive integration of UASs into the NAS.

\section{Recurrent Training Requirements}

The survey also addressed recurrent training requirements for manned and unmanned aircraft as a comparison to determine the need for annual recurrent training. These two questions (Q30/31) were specifically designed to compare UASs recurrent training requirements and FAA recurrent training requirements from the perspective of the UAS community.

Twenty-five survey respondents (64.1\%) "Strongly Agree" or "Agree," six respondents (15.4\%) "Strongly Disagree" or "Disagree," and five respondents (12.8\%) were "Undecided" that their organization requires annual re-currency training in aircraft systems and in emergency procedures for the manned aircraft flown. A majority of respondents believe recurrent training is required by their organization for the manned aircraft they fly.

Twenty-eight survey respondents (71.8\%) "Strongly Agree" or "Agree," nine respondents (23.1\%) "Strongly Disagree" or "Disagree," and two respondents (5.1\%) were "Undecided" that their organization requires annual re-currency training. A majority of respondents believe recurrent training is required. Although the number of respondents that do not agree increased, what is most interesting is that the UASs community is more inclined to believe recurrent training is required for unmanned aircraft than manned aircraft.

\section{Unmanned Aircraft Systems Operations Safety Plan}

One additional question (Q25) not related to NTSB Safety Recommendations was added to solicit input on the development of a "safety plan." Respondents were asked to respond to the following statement: "My organization has developed a safety plan, which ensures that hazards to the National Airspace System and persons on the ground introduced by UAS operations are identified and that necessary actions are taken to mitigate the corresponding safety risks to the public." Thirty-five respondents $(89.7 \%)$ indicated "Strongly Agree" or "Agree" with this statement. Three respondents (7.7\%) were undecided and one respondent (2.6\%) was in disagreement with the statement. This is an important finding in that it is indicative that the UASs community recognizes the implementation of a safety plan.

\section{Conclusion}

The overarching view of this study indicates that CBP has addressed the safety recommendation identified in the NTSB's Omaha 10 accident investigation. Overall, 
survey respondents are in agreement with most of the actions taken to address the NTSB's Safety Recommendations. The data reported in Tables 4 and 5 clearly indicate that those within the UASs community believe that their organizations have taken a proactive approach to an external review of their operations. There is only one safety recommendation that respondents indicated disagreement that their organization had taken appropriately measures to correct. It is understandable that there are reservations regarding the recording of radio transmissions and telephone conversations, and the potential dissemination of "classified" information. The researchers do not believe this is reflects an inability of the UASs community to safely operate UA in the NAS. Overall, the UASs community has demonstrated a professional approach to the NTSB Safety Recommendations that parallels their civil aviation counterparts. In fact, as the data indicate, the majority of UASs pilots and sensor operators have FAA qualifications and practical experience operating aircraft in the NAS; the widespread acceptance of the NTSB's Safety Recommendations is not surprising.

What may be the most interesting finding of the study is the extent of disagreement that contemporary aspects of human factors have been addressed by the UASs community. As it relates to the answer to the underlying question of this study: Is the safety culture within the UASs community congruent with the culture of safety that exists among the civil aviation community; thereby enabling cohesive and safe operations within the NAS, the response to these two questions alone would indicate that the UASs community needs to address human factors to the same extent as do their counterparts in the civilian aviation community.

Areas for further research would include a determination on whether or not UASs Pilots and Sensor operators should be certificated. Also, the question of if Pilots and Sensor operators should also be required to have a Medical certificate, and what class, needs to be answered. 


\section{References}

Anderson, P. S. (2002). Development of a UAV ground control station (Unpublished master's thesis). Linköping University, Sweden. Retrieved from http://api.ning.com/files/ga5AVWy8xTu8cx9rHdzJ73Epc*dzb0uy*UPe0O8wFxo gMF6WNRW8StK3xxzkG2iBk16kNFpYTZe80NgM8kbXOiyxrEwUXIt/GroundControlStation.pdf

Carrigan, G., Long, D., Cummings, M. L., \& Duffner, J. (2008, June). Human factors analysis of Predator B crash. Proceedings of AUVSI 2008: Unmanned Systems North America, USA. Retrieved from http://web.mit.edu/aeroastro/labs/halab/papers/Carrigan_AUVSI.pdf

Clary, D. E. (1988, April). The Bekka Valley - a case study (Report Number 88-0550). Retrieved from http://www.dtic.mil/cgibin/GetTRDoc?AD=ADA192545\&Location=U2\&doc=GetTRDoc.pdf

Cummings, M. L., Kirschbaum, A. R., Sulmistras, A., \& Platts, J. T. (n.d.). STANAG 4586 human supervisory control implications. Retrieved from http://www.scribd.com/doc/36452536/STANAG-UVS

Diamond, T. T., Rutherford, A. L., \& Taylor, J. B. (2009). Cooperative unmanned aerial surveillance control system architecture (Master's thesis). Retrieved from http://www.dtic.mil/cgi-bin/GetTRDoc?AD=ADA495577 (AFIT/GSE/ENV/09M07).

Doherty, P., Granlund, G., Kuchcinski, K., Sandewall., Nordberg, K., Skarman, E., \& Wiklund, J. (2000). The WITAS Unmanned Aerial Vehicle project. In W. Horn (Ed.), Proceedings of the 14th European Conference on Artificial Intelligence (ECAI-00) (pp. 747-755). Washington, DC: IOS Press. Retrieved from http://books.google.com/books?id=FsHsCt127IgC\&printsec=frontcover\#v=onepa ge\&q\&f=false

Hayhurst, K. J., Maddalon, J. M., Miner, P. S., Szatkowski, G. N., Ulrey, M. L., DeWalt, M. P., \& Spitzer, C. R. (2007). Preliminary considerations for classifying hazards of unmanned aircraft systems (NASA/TM-2007-214539). Retrieved from http://shemesh.larc.nasa.gov/people/jmm/NASA-2007-tm214539.pdf

Koenig, B. (2012, February 8). Bill authorizes use of unmanned drones in U.S. airspace. New American. Retrieved from http://thenewamerican.com/usnews/politics/10807-bill-authorizes-use-ofunmanned-drones-in-us-airspace 
McLain, T. W. (1999). Coordinated control of unmanned air vehicles. Wright-Patterson Air Force Base, OH: Air Vehicles Directorate. Retrieved from http://scholar.google.com/scholar_url?hl=en\&q=http://citeseerx.ist.psu.edu/viewd oc/download\%3Fdoi\%3D10.1.1.33.2291\%26rep\%3Drep1\%26type\%3Dpdf\&sa= X\&scisig=AAGBfm3z6JDqHD8pAbvMVvsKwGdOq0NueA\&oi=scholarr

National Transportation Safety Board. (2007, October 24). Safety recommendations (A07-70 through A-07-86). Washington, DC: Author.

Nullmeyer, R., Herz, R., \& Montijo, G. (2009). Training interventions to reduce Air Force Predator mishaps (Report Number AFRL-RH-AZ-PR-2009-0002).

Retrieved from http://www.dtic.mil/cgibin/GetTRDoc?AD=ADA501747\&Location=U2\&doc=GetTRDoc.pdf

Sullivan, P. S., \& Keenan, D. (2006). Omaha 10 factual report (CH106MA121). Retrieved from the National Transportation and Safety Board website: http://dms.ntsb.gov/aviation/AccidentReports/q5fpru45nktesb45iyuhjm451/M030 82012120000.pdf

U.S. Department of Defense, Office of the Secretary of Defense. (2005, August). Unmanned aircraft systems (UAS) roadmap, 2005-2030. Washington, DC: Author.

Werfelman, L. (2007, December). Causal factors: Reining in the UAS. Aerosafety World: The Journal of Flight Safety Foundation, 2(1), 42-46.

Williams, K. W. (2006, April). Human factors implications of unmanned aircraft accidents: flight control problems (DOT/FAA/AM-06/8). Retrieved http://www.raytheon.com/capabilities/rtnwcm/groups/iis/documents/content/rtn_ii s_ucs_faa2.pdf

Yenne, B. (2004). Attack of the Drones: A history of unmanned aerial combat. St. Paul, MN: Zenith. 